\title{
Secretion Assay in Shigella flexneri
}

Jonathan Reinhardt and Michael Kolbe*

Max-Planck-Institute for Infection Biology, Berlin, Germany

*For correspondence: kolbe@mpiib-berlin.mpg.de

[Abstract] Shigella flexneri (S. flexneri) is a Gram-negative bacterium that causes gastroenteritis and shigellosis in humans. In order to establish and maintain an infection, S. flexneri utilises a type three secretion system (T3SS) to deliver virulence factors called effector proteins into the cytoplasm of host cells, facilitating e.g. uptake into the host cell and escape from the endosome. Secretion through the T3SS is tightly regulated and is usually triggered by host-cell contact, but can also be artificially stimulated in vitro. In this assay, the dye Congo red is used to induce T3SS-dependent secretion of S. flexneri (Parsot et al., 1995) and secreted proteins are concentrated from the culture supernatant by precipitation with trichloroacetic acid. The assay presented here can easily be adapted to the secretion analysis of other bacteria utilising a T3SS, such as Salmonella typhimurium, which constitutively secrete when grown at $37^{\circ} \mathrm{C}$ (Collazo et al., 1995; Pegues et al., 1995), or pathogenic species of Yersinia, where secretion can be induced by calcium deprivation (Heesemann et al., 1986; Forsberg et al., 1987).

\section{Materials and Reagents}

1. Tryptone soy agar (TSA) (Carl Roth, catalog number: CP70.1)

2. Shigella flexneri (strain M90T) on a Congo red tryptone soy agar plate

3. 99\% Trichloroacetic acid (TCA) (Carl Roth, catalog number: 8789 )

4. Acetone (Merck KGaA, catalog number: 1000142511)

5. TRIZMA base (Sigma-Aldrich, catalog number: T1503)

6. Sodium dodecyl sulfate (SDS) (Sigma-Aldrich, catalog number: L3771)

7. Bromophenol blue (Sigma-Aldrich, catalog number: B5525)

8. Glycerol (Sigma-Aldrich, catalog number: G7757)

9. 2-Mercaptoethanol (Sigma-Aldrich, catalog number: M3148)

10. LB medium (Carl Roth, catalog number: X968.2) (see Recipes)

11. Tryptone soy agar plates (see Recipes)

12. Sample buffer (see Recipes)

13. Congo red stock solution (Sigma-Aldrich, catalog number: C6767) (see Recipes) Note: Used as $5 \mathrm{mg} / \mathrm{ml}$ stock solution. 


\section{Equipment}

1. $5 \mathrm{ml}$ syringes (Henke-Sass, Wolf, catalog number: $5050.000 \mathrm{~V} 0$ )

2. $0.2 \mu \mathrm{m}$ syringe filters (GE Healthcare, catalog number: 10462200)

3. Culture tubes

4. $50 \mathrm{ml}$ Erlenmeyer flasks

5. $1.5 \mathrm{ml}$ microtubes

6. Microfuge

7. $37^{\circ} \mathrm{C}$ shaking incubator

8. Laminar flow hood

9. Spectrophotometer

\section{Procedure}

1. Prepare a pre-culture by inoculating $2 \mathrm{ml}$ of LB medium with a single colony of $\mathrm{S}$. flexneri from a Congo red tryptone soy agar plate and grow overnight $(\sim 16 \mathrm{~h})$ at $37^{\circ} \mathrm{C}$ with agitation (180 rpm).

Note: Ensure that the colonies used are secretion-competent, i.e. forming red colonies on the plate due to Congo red absorption (Payne and Finkelstein, 1977).

2. Subculture by diluting $100 \mu \mathrm{l}$ of the pre-culture in $10 \mathrm{ml}$ of fresh LB medium (i.e. 1:100 dilution).

3. Grow to $\mathrm{OD}_{600}$ (absorbance at $600 \mathrm{~nm}$ ) of $0.3-0.4$ at $37^{\circ} \mathrm{C}$ with agitation.

Note: In case genes from expression plasmids are to be induced, this should be done at $O D_{600}$ of $\sim 0.1$.

4. Add Congo red to a final concentration of $200 \mu \mathrm{g} / \mathrm{ml}$ (i.e. $400 \mu \mathrm{l}$ of $5 \mathrm{mg} / \mathrm{ml} \mathrm{stock} \mathrm{solution}$ to $10 \mathrm{ml}$ of culture).

5. Grow for $2-3 \mathrm{~h}$ at $37^{\circ} \mathrm{C}$ with agitation - the final $\mathrm{OD}_{600}$ of the culture should be between 2 and 3.

6. Pellet cells by centrifugation for $10 \mathrm{~min}$ at $10,000 \times \mathrm{g}$ and $4{ }^{\circ} \mathrm{C}$.

Note: For the following TCA precipitation a supernatant volume corresponding to $1 \mathrm{ml}$ culture of $O D_{600}=2$ is used, meaning that centrifugation of $1.4 \mathrm{ml}$ of culture in $1.5 \mathrm{ml}$ tubes should be sufficient (considering the dead volume of the filter units in step 7).

7. Transfer the supernatant to the $5 \mathrm{ml}$ syringes and filter through $0.2 \mu \mathrm{m}$ filters.

Note: For maximum yield remove the piston from the syringe and add the filter. Transfer the supernatant into the syringe and replace the piston- the additional air will minimize the volume lost in the filter. 
8. Take a volume of filtered supernatant corresponding to $1 \mathrm{ml}$ culture of $\mathrm{OD}_{600}=2$ and add ice-cold $99 \%$ trichloroacetic acid to a final concentration of $10 \%(\mathrm{v} / \mathrm{v})$.

Note: Congo red will turn blue at this point and precipitate as well.

9. Transfer the tubes to $-20^{\circ} \mathrm{C}$ for $20 \mathrm{~min}$.

10. Centrifuge at top speed $(12,000 \times g$ to $16,000 \times g)$ in a microfuge for $30 \mathrm{~min}$ at $4{ }^{\circ} \mathrm{C}$.

11. Carefully discard the supernatant and rinse the pellet with $1 \mathrm{ml}$ ice-cold acetone.

12. Centrifuge again $\left(12,000 \times g\right.$ to $\left.16,000 \times g, 30 \mathrm{~min}, 4^{\circ} \mathrm{C}\right)$.

13. Carefully remove the supernatant and let the pellet air dry for $15 \mathrm{~min}$.

14. Resuspend the pellet in sample buffer.

Note: The volume required may vary with the method of detection after electrophoresis: for analysis by Coomassie staining, resuspension in $25 \mu \mathrm{l}$ to $100 \mu \mathrm{l}$ will produce sufficiently strong bands.

15. Analyse by SDS-PAGE through $12 \%$ acrylamide gels.

\section{Representative data}

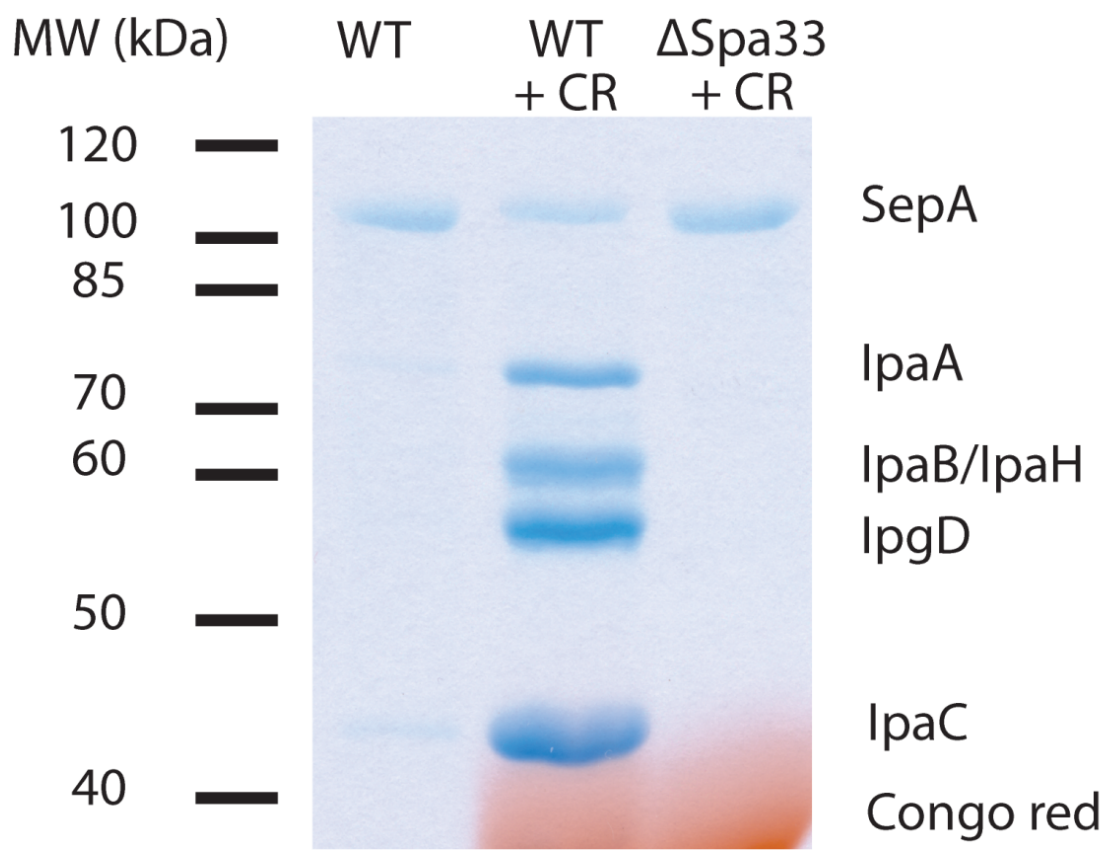

Figure 1. Example of secretion from $S$. flexneri. TCA-precipitated pellets were resuspended in $25 \mu \mathrm{l}$ of sample buffer and $20 \mu \mathrm{l}$ loaded on a $12 \%$ polyacrylamide gel. $\mathrm{CR}=$ Congo red. $\triangle$ Spa33 is a T3SS-deficient mutant. IpaA, IpaB, IpaH, IpgD and IpaC are effector proteins. SepA is a T3SS-independent secreted protein and serves as an intrinsic loading control. 
Note: IpaD may be discernible at $37 \mathrm{kDa}$, but is often obscured by Congo red. Congo red will return to its original color by soaking the gel in $100 \mathrm{mM}$ Tris (pH 9.0) after Coomassie staining.

\section{$\underline{\text { Recipes }}$}

1. LB medium

25 g LB medium powder

Water to $1 \mathrm{~L}$

Note: It may be necessary to adjust the $\mathrm{pH}$ to 7.0-7.5 with a few drops of $1 \mathrm{M} \mathrm{NaOH}$ solution. This is usually not required, since LB medium is weakly buffered in this $\mathrm{pH}$ range.

Autoclave the solution

2. Tryptone soy agar plates

$20 \mathrm{~g}$ Tryptone soy agar powder

$0.05 \mathrm{~g}$ Congo red powder

Water to $500 \mathrm{ml}$

Note: It may be necessary to adjust the $\mathrm{pH}$ to 7.0-7.5 with a few drops of $1 \mathrm{M} \mathrm{NaOH}$ solution. This is usually not required, since TSA is weakly buffered in this $\mathrm{pH}$ range.

Autoclave the solution

Cool to $\sim 50{ }^{\circ} \mathrm{C}$ and pour plates

3. Sample buffer

SDS-loading buffer with increased buffer capacity

$10 \%$ glycerol (v/v)

$360 \mathrm{mM}$ Tris- $\mathrm{HCl}(\mathrm{pH} 6.8)$

$2 \%$ SDS (w/v)

1.25\% 2-mercaptoethanol (v/v)

$0.01 \%$ bromophenol blue (w/v)

4. Congo red stock solution

$5 \mathrm{mg}$ of Congo red powder per $\mathrm{ml}$ water

Note that the dye content in the Congo red powder used here is $\sim 40 \%$ and may differ between manufacturers. The stock solution is stable at room temperature for several months. When kept in the fridge or at $-20{ }^{\circ} \mathrm{C}$, Congo red may precipitate. Warm the solution to $37^{\circ} \mathrm{C}$ to re-dissolve. 


\section{Acknowledgments}

This work has been financially supported by the European Research Council under the European Community's Seventh Framework Programme (FP7/2007-2013) and a Ph.D. Scholarship from the International Max Planck Research School for Infectious Diseases and Immunology.

The protocol presented here has been adapted from Dohlich et al. (2014).

\section{$\underline{\text { References }}$}

1. Collazo, C. M., Zierler, M. K. and Galan, J. E. (1995). Functional analysis of the Salmonella typhimurium invasion genes invl and invJ and identification of a target of the protein secretion apparatus encoded in the inv locus. Mol Microbiol 15(1): 25-38.

2. Dohlich, K., Zumsteg, A. B., Goosmann, C. and Kolbe, M. (2014). A substrate-fusion protein is trapped inside the Type III Secretion System channel in Shigella flexneri. PLoS Pathog 10(1): e1003881.

3. Forsberg, A., Bolin, I., Norlander, L. and Wolf-Watz, H. (1987). Molecular cloning and expression of calcium-regulated, plasmid-coded proteins of $Y$. pseudotuberculosis. Microb Pathog 2(2): 123-137.

4. Heesemann, J., Gross, U., Schmidt, N. and Laufs, R. (1986). Immunochemical analysis of plasmid-encoded proteins released by enteropathogenic Yersinia sp. grown in calciumdeficient media. Infect Immun 54(2): 561-567.

5. Parsot, C., Menard, R., Gounon, P. and Sansonetti, P. J. (1995). Enhanced secretion through the Shigella flexneri Mxi-Spa translocon leads to assembly of extracellular proteins into macromolecular structures. Mol Microbiol 16(2): 291-300.

6. Payne, S. M. and Finkelstein, R. A. (1977). Detection and differentiation of ironresponsive avirulent mutants on congo red agar. Infect Immun 18(1): 94-98.

7. Pegues, D. A., Hantman, M. J., Behlau, I. and Miller, S. I. (1995). PhoP/PhoQ transcriptional repression of Salmonella typhimurium invasion genes: evidence for a role in protein secretion. Mol Microbiol 17(1): 169-181. 